Article

\title{
Effects of GGT and C-S Lyase on the Generation of Endogenous Formaldehyde in Lentinula edodes at Different Growth Stages
}

\author{
Xiaoyu Lei ${ }^{1}$, Shuangshuang Gao ${ }^{1}$, Xi Feng ${ }^{2}$, Zhicheng Huang ${ }^{1}$, Yinbing Bian ${ }^{3}$, Wen Huang ${ }^{1, *}$ \\ and Ying Liu $1, * \mathbb{D}$ \\ 1 College of Food Science and Technology, Huazhong Agricultural University, Wuhan 430070, China; \\ xiaoyulei1988@126.com (X.L.); 13720161459@163.com (S.G.); HuangZhiCheng1210@163.com (Z.H.) \\ 2 Department of Nutrition, Food Science and Packaging, California State University, San Jose, CA 95192, USA; \\ xi.feng@sjsu.edu \\ 3 Institute of Applied Mycology, Huazhong Agricultural University, Wuhan 430070, China; \\ bianyb.123@163.com \\ * Correspondence: huangwen@mail.hzau.edu.cn (W.H.); yingliu@mail.hzau.edu.cn (Y.L.); \\ Tel.: +86-13407161906 (Y.L.)
}

Academic Editor: Stefano Serra

Received: 13 October 2019; Accepted: 18 November 2019; Published: 20 November 2019

\begin{abstract}
Endogenous formaldehyde is generated as a normal metabolite via bio-catalysis of $\gamma$-glutamyl transpeptidase (GGT) and L-cysteine sulfoxide lyase (C-S lyase) during the growth and development of Lentinula edodes. In this study, we investigated the mRNA and protein expression levels, the activities of GGT and C-S lyase, and the endogenous formaldehyde content in L. edodes at different growth stages. With the growth of $L$. edodes, a decrease was found in the mRNA and protein expression levels of GGT, while an increase was observed in the mRNA and protein expression levels of C-S lyase as well as the activities of GGT and C-S lyase. Our results revealed for the first time a positive relationship of formaldehyde content with the expression levels of Csl (encoding Lecsl) and Lecsl (C-S lyase protein of Lentinula edodes) as well as the enzyme activities of C-S lyase and GGT during the growth of L. edodes. This research provided a molecular basis for understanding and controlling the endogenous formaldehyde formation in Lentinula edodes in the process of growth.
\end{abstract}

Keywords: Lentinula edodes; endogenous formaldehyde; GGT; C-S lyase; expression levels

\section{Introduction}

Lentinula edodes (shiitake mushroom) is the second-most popular edible mushrooms in the world (the No. 1 is Agaricus bisporus), due to its high nutritional and medicinal values as well as the unique flavor [1-4]. Lenthionine (1,2,3,5,6-pentathiepane), the unique aroma of L. edodes [5,6], is derived from lentinic acid in a two-step enzymatic reaction $[7,8]$. In the reaction, the lentinic acid is catalyzed by $\gamma$-glutamyl transpeptidase (GGT) and L-cysteine sulfoxide lyase (C-S lyase) to generate the unique flavor compounds, including lenthionine [8-10]. Nevertheless, formaldehyde is also produced in this metabolic pathway (Figure 1).

Formaldehyde, a mutagen, can be found in the air, natural and processed foods, especially in frozen food and dry foods, and is classified as a human carcinogen by the International Agency for Research on Cancer (IARC) of World Health Organization [11]. The maximum daily dose reference for formaldehyde is defined as about $0.2 \mathrm{mg} / \mathrm{kg}$ body weight per day by the US Environmental Protection Agency. Even small doses of formaldehyde can cause various symptoms of physical discomfort [12]. However, the formaldehyde contents are $1-20 \mathrm{mg} / \mathrm{kg}$ in various fruits, vegetables, meat and fish 
products [13]. In recent years, the amount of formaldehyde in L. edodes has raised the public concerns about food safety. For instance, high levels of formaldehyde (100-300 mg/kg) have been detected in shiitake mushroom samples produced in UK and Chinese [14]. Japanese researchers have reported that formaldehyde is generated in the growth process of L. edodes as a normal metabolite to form its unique flavor [15].

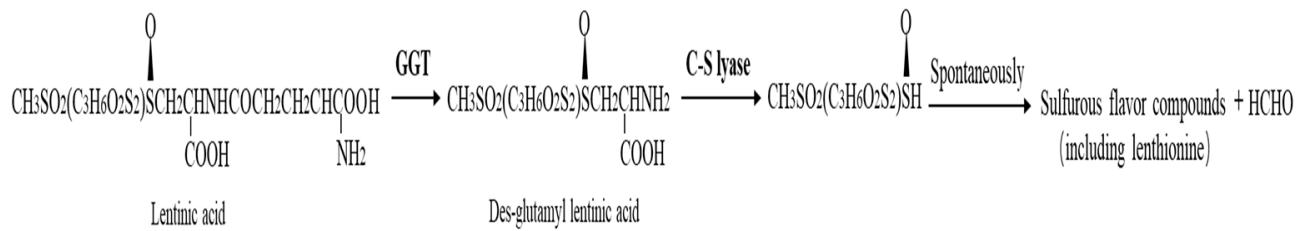

Figure 1. Proposed pathway for the generation of sulfurous flavor compounds and endogenous formaldehyde in Lentinula edodes.

Meanwhile, $\gamma$-glutamyl transpeptidase (GGT; EC 2.3.2.2) is an enzyme that catalyzes the transfer of the $\gamma$-glutamyl group of glutathione and related $\gamma$-glutamyl amides to water (hydrolysis) or to amino acids and peptides (transpeptidation) [16]. Cysteine sulfoxide lyase (EC 4.4.1.4) is a pyridoxal-5-phosphate (PLP) dependent enzyme and assigned to the class I family of PLP dependent enzymes [17]. In our previous work, the two enzymes were purified and characterized to play a significant biochemical role in the generation of endogenous formaldehyde in L. edodes [18]. Additionally, the gene of Csl encoding Lecsl (L. edodes C-S lyase) was cloned [19].

However, little is known about the relationship of GGT and C-S lyase with the production of formaldehyde in L. edodes. Thus, the aims of the present work were to determine the mRNA and protein expression levels and the activities of GGT and C-S lyase at different growth stages of shiitake mushrooms and to explore their correlations with endogenous formaldehyde production in L. edodes. This research could provide a molecular basis to understand the regulatory mechanisms of endogenous formaldehyde generation in L. edodes during the growth process.

\section{Results and Discussion}

\subsection{Gene Expression of Ggtl and Csl}

The expressions of Ggtl (encoding Leggt) and Csl (encoding Lecsl) during fruiting body development were analyzed by examining their transcript levels using real-time quantitative PCR. Both Ggtl and Csl were expressed at all the five stages of fruit-body development: mycelia, grey, young fruiting body, immature fruiting body and mature fruiting body, but differed in their expression patterns (Figure 2). Specifically, the transcript level of Ggtl decreased during the growth process, in contrast to an increase for Csl. Additionally, Ggtl showed the highest and lowest expression level in mycelia and mature fruiting body, respectively, which was just the opposite for Csl. There was approximately 1.5-fold difference between the highest and lowest expression levels in the two genes. Analysis of variance showed a significant difference in the Ggtl and Csl expression levels between mycelia and fruiting body stages, while Ggtl exhibited a significantly different expression in the four fruiting body stages $(p<0.05)$.

Based on our in-house transcriptome data, the expression pattern of $G g t l$ in different growth stages was basically in line with the quantitative RT-PCR results of our experiment. Csl was first reported as a gene involved in the generation of unique aroma of L. edodes [19]. In an early report, Csl displayed no obvious change in the expression level at 1,2 and $3 \mathrm{~h}$ in the stage of mycelium or fruiting body during hot-air drying [20], which were basically consistent with our research results. Overall, there was a gradual decline of Ggtl expression level in different growth stages and an obvious increase of Csl expression level between mycelia and fruiting body stages. 


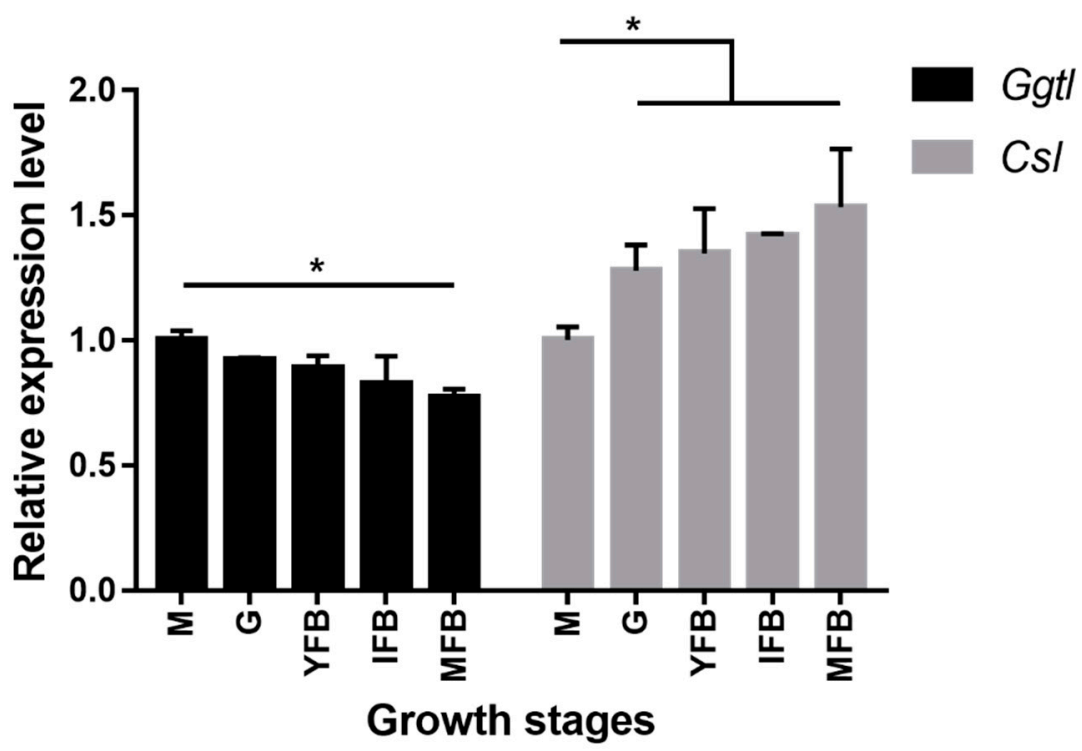

Figure 2. Expression of Ggtl and Csl during fruit-body development of Lentinula edodes strain W1. Relative expression during five growth stages, M, mycelia; G, grey; YFB, young fruiting body; IFB, immature fruiting body; MFB, mature fruiting body. Transcript levels of Ggtl (black bars) and Csl (gray bars) were determined by real-time quantitative RT-PCR analysis and normalized against Actinl. The expressions during the $\mathrm{M}$ stage were taken as 1 . Error bars indicate standard deviation for three independent experiments. ${ }^{*} p<0.05$, ANOVA tests by Duncan's indicate significant differences.

\subsection{Western Blot of Leggt and Lecsl}

The protein expression levels of Leggt (GGT protein of L. edodes) and Lecsl (C-S lyase protein of $L$. edodes) in L. edodes at different growth stages were determined by Western blot using $\beta$-actin as an internal reference (Figure 3A,B) [21]. Notably, Leggt exhibited three bands, which conformed to previous reports $[22,23]$, and their gray values showed a gradual decrease in the five stages. A previous study has shown that a mature gamma-glutamyl transpeptidase consists of one polypeptide chain and can be divided into a large and a small subunit by self-catalysis at the highly conserved threonine [24]. Correspondingly, three bands were shown in our Western blot analysis of Leggt. The protein expression levels showed a decrease in Leggt while a gradual increase in Lecsl during the growth process of L. edodes (Figure 3C). The overall trend of protein expression levels was similar to that of mRNA expression levels. Moreover, the two proteins showed significant differences in all the five samples. The changes between the highest and lowest expression levels of Leggt and Lecsl were 2.1-fold and 1.9-fold, respectively. This is the first report on the expression levels of these two enzyme proteins in shiitake mushrooms. Our data indicated that the expression of Leggt decreased while Lecsl increased across the five growth stages of $L$. edodes.

\subsection{Enzyme Activities of GGT and C-S Lyase}

Figure 4A,B show the activity of GGT and C-S lyase at five different growth stages of L. edodes. The enzyme activities of GGT and C-S lyase were the lowest at the mycelia stage (4.7 U/g of GGT, 17.1 $\mathrm{U} / \mathrm{g}$ of C-S lyase) and showed an obvious increase at the four fruiting body stages. Moreover, the GGT enzyme activity was relatively lower at the young fruiting body stage, while the C-S lyase enzyme activity showed no significant differences at the later four fruiting body stages $(p<0.05)$. 
A

Leggt

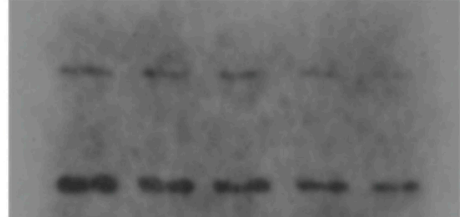

$\beta$-actin

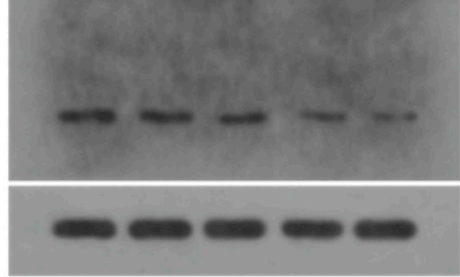

B

Lecsl

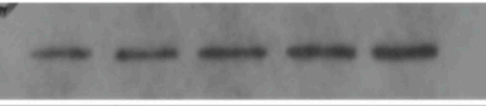

$\beta$-actin

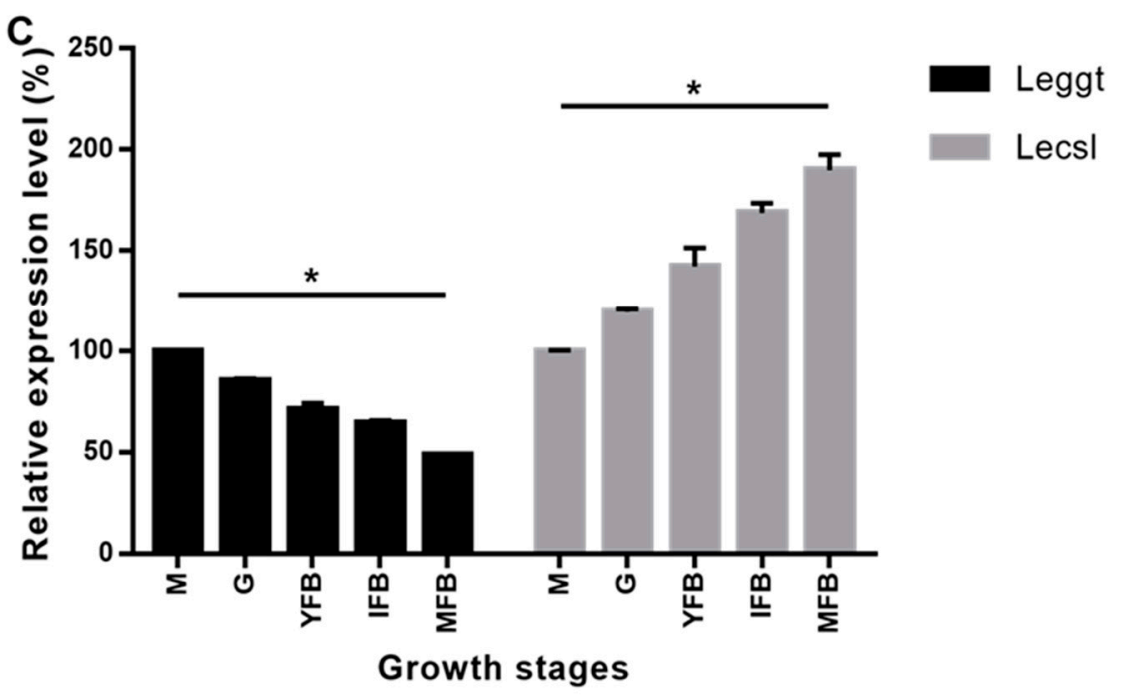

Figure 3. (A) Protein levels of Leggt at five stages of growth. (B) Protein levels of Lecsl at five stages of growth. (C) Relative expression of Leggt and Lecsl during five growth stages. $\beta$-actin protein was used as loading control, and the expressions during the $\mathrm{M}$ stage were taken as $100 \%$. M, mycelia; $\mathrm{G}$, grey; YFB, young fruiting body; IFB, immature fruiting body; MFB, mature fruiting body. Error bars indicate standard deviation for three independent experiments. ${ }^{*} p<0.05$, ANOVA tests by Duncan's indicate significant differences.

Our experimental data $(40.2-54.1 \mathrm{U} / \mathrm{g})$ were consistent with the results of Huang et al., who reported that the GGT enzyme activity at the four fruiting body stages ranged from 40 to $80 \mathrm{U} / \mathrm{g}$, with a similar difference at each stage in the fruiting body samples [25]. This is the first report about the C-S lyase enzyme activities of L. edodes at different growth stages. The C-S lyase enzyme activities in the present study (17.1-3575.6 U/g) were obviously lower than those determined by Xu et al. under high-temperature pre-drying $\left(45,55,65\right.$ and $75^{\circ} \mathrm{C}$ for $\left.30 \mathrm{~min}\right)$ of air-dried $\left(45^{\circ} \mathrm{C}\right.$ for $4.5 \mathrm{~h}, 60^{\circ} \mathrm{C}$ for $\left.4 \mathrm{~h}\right)$ L. edodes (80.17-100.54 U/mg) [26]. Liu et al. reported that the C-S lyase from L. edodes showed the optimum activity at $40^{\circ} \mathrm{C}$ and was stable at $20-60^{\circ} \mathrm{C}$ [18]. $\mathrm{Csl}$ has been demonstrated as a heat-inducible gene [27], so the activity of protein encoded by it could be improved greatly. In this study, our samples were generally collected at $25^{\circ} \mathrm{C}$, which was far below the drying treatment temperature $\left(>45^{\circ} \mathrm{C}\right)$, so the C-S lyase enzyme activity was lower than that treated under high temperature. Collectively, the C-S lyase enzyme activity showed no significant difference at the four fruiting body stages $(p<0.05)$. 

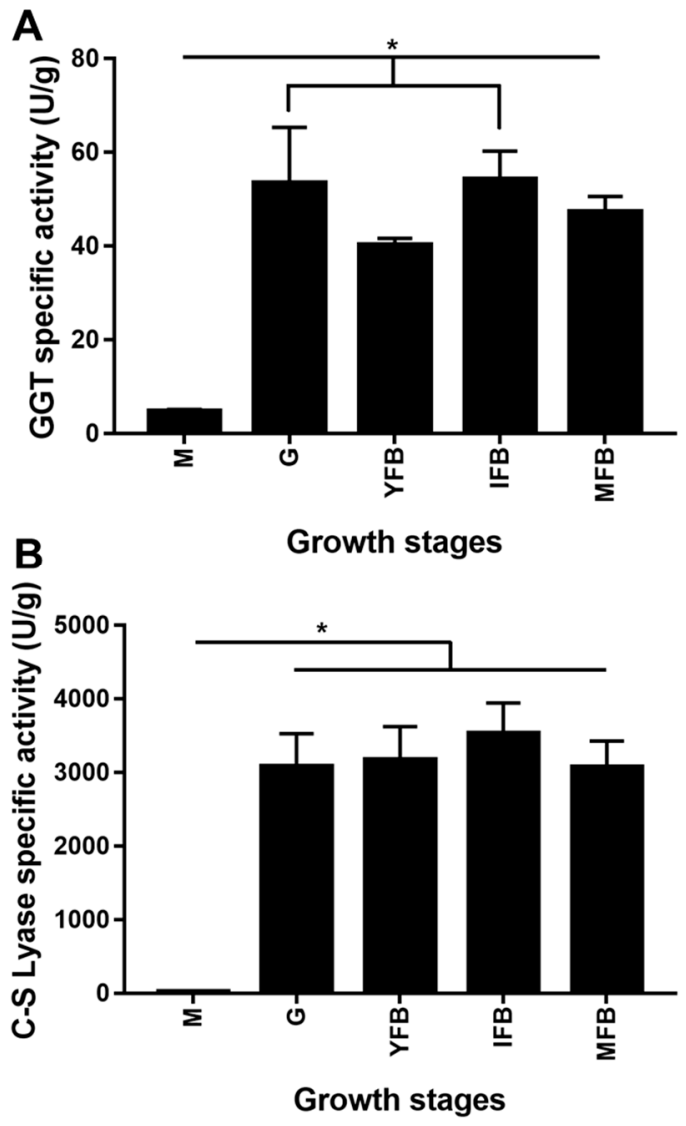

Figure 4. (A) The specific activity of GGT at the five growth stages. The reaction mixture containing the enzyme and the GPNA substrate was analyzed under standard conditions, and the residual activity was calculated. (B) The specific activity of C-S lyase at the five growth stages. The reaction mixture containing the enzyme and S-ethyl-L-cysteine sulfoxide substrate was analyzed under standard conditions, and the residual activity was calculated. M, mycelia; G, grey; YFB, young fruiting body; IFB, immature fruiting body; MFB, mature fruiting body. Error bars indicate standard deviation for three independent experiments. ${ }^{*} p<0.05$, ANOVA tests by Duncan's indicate significant differences.

However, there was a marked difference between the two enzymes activities and their expression levels at the mycelia stage. GGT performs different functions in peptide transferase reaction and hydrolysis reaction under different conditions [16]. Lecsl has already been demonstrated to have one active center involved in the binding of the two substrates, S-methyl-L-cysteine sulfoxide and L-cysteine, with both cysteine sulfoxide lyase and cysteine desulfurase activities [19]. In addition, there are many factors affecting enzyme activity, such as $\mathrm{pH}$, temperature, metal ions and so on. The two enzymes activities were reported to be stimulated by $\mathrm{Na}^{+}, \mathrm{K}^{+}, \mathrm{Mg}^{2+}$ and $\mathrm{Ca}^{2+}$ ions [18]. The environment conditions are very different between the mycelia stage and the four fruiting body stages, since the former belongs to vegetative growth and the latter belong to reproductive growth. These observations suggested that there might be a sort of regulatory mechanism that activated the two enzymes during the fruiting body stages while stayed inactive at the mycelial stage, which we failed to detect in this study.

\subsection{Endogenous Formaldehyde Content in L. edodes}

Figure 5 showed the content of endogenous formaldehyde in L. edodes at different growth phases. Compared with the mycelia stage, the endogenous formaldehyde content increased significantly ( $p$ $<0.05$ ) at the four fruiting body stages, reached the maximum at the immature fruiting body stage and slightly decreased at the mature fruiting body stage. The trend of formaldehyde content at these 
four stages accorded with the findings of Huang et al. and Li et al. [25,28], which ranged from 13 to $89 \mathrm{mg} / \mathrm{kg}$ (dry weight) at all five stages. Mason et al. determined the formaldehyde content as 8-24 $\mathrm{mg} / \mathrm{kg}$ in fresh shiitake mushrooms [29].

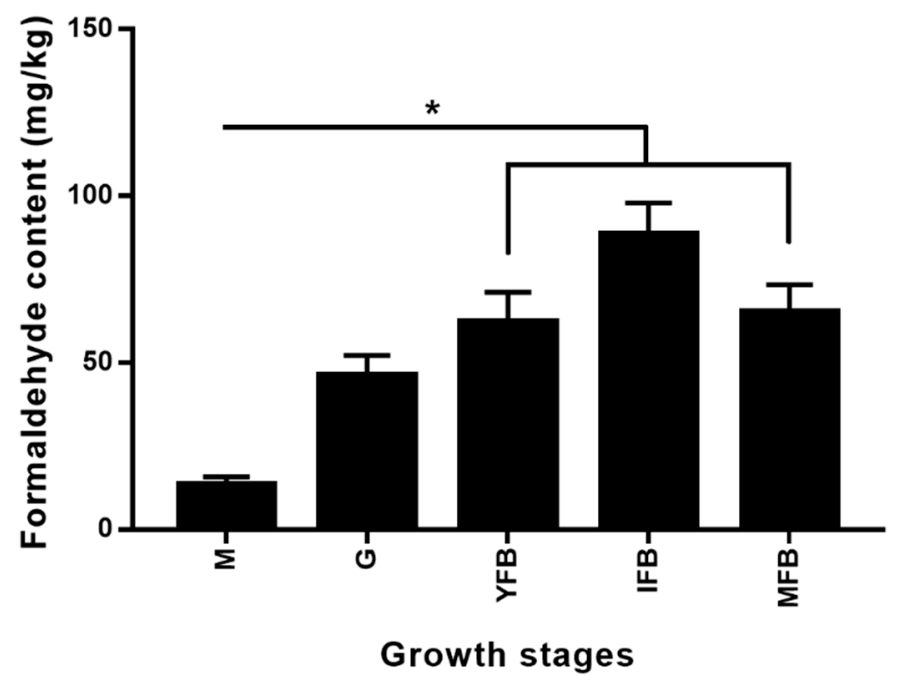

Figure 5. Endogenous formaldehyde content of L. edodes strain W1 at different growth stages. M, mycelia; G, grey; YFB, young fruiting body; IFB, immature fruiting body; MFB, mature fruiting body. Error bars indicate standard deviation for three independent experiments. ${ }^{*} p<0.05$, ANOVA tests by Duncan's indicate significant differences.

The endogenous formaldehyde content at different growth stages showed a similar change trend to that of C-S lyase enzyme activity. The formaldehyde content of L. edodes during the drying has been reported to range between 150 and $400 \mathrm{mg} / \mathrm{kg}$ (dry weight) [26]. The increase of the two enzyme activities in the drying process also led to a significant increase in the endogenous formaldehyde content. Xu et al. indicated that GGT and C-S lyase were involved in formaldehyde formation and their activities were positively correlated with formaldehyde content [26]. Although the activities of the GGT and C-S Lyase were higher in IFB than in the other four stages, the differences were not significant. The endogenous formaldehyde was found to be produced from oxidative decomposition of the folate backbone and creates a benign $1 C$ unit that can sustain essential metabolism in human cells [30]. Additionally, L. edodes also contains folic acid. Therefore, whether there are other enzymes and metabolic pathways involved in the generation of endogenous formaldehyde in L. edodes needs to be further studied.

\subsection{Correlation Analysis}

The effects of GGT and C-S lyase on the generation of endogenous formaldehyde in Lentinula edodes at different growth stages were intuitively determined by correlation analysis (Table 1). The formaldehyde content of $L$. edodes showed a positive and significant $(p<0.01)$ correlation $(\mathrm{R})$ with the expression level of Csl and Lecsl and the activity of C-S lyase and GGT $(0.746,0.805,0.867$ and 0.768 , respectively), while a negative relationship with the expression level of Ggtl and Leggt ( -0.699 and $-0.787 ; p<0.01)$. 
Table 1. Correlations (R) of the formaldehyde contents in L. edodes with Ggtl expression levels, Csl expression levels, Leggt expression levels, Lecsl expression levels, GGT enzyme activities and C-S lyase enzyme activities at different growth stages.

\begin{tabular}{cc}
\hline Properties & Formaldehyde Content \\
\hline Ggtl expression levels (mRNA) & $-0.699^{* *}$ \\
Csl expression levels (mRNA) & $0.746^{* *}$ \\
Leggt expression levels (Protein) & $-0.787^{* *}$ \\
Lecsl expression levels (Protein) & $0.805^{* *}$ \\
GGT enzyme activities & $0.768^{* *}$ \\
C-S lyase enzyme activities & $0.867^{* *}$ \\
\hline
\end{tabular}

** significant at 0.01 level.

Japanese researchers pointed out that the formaldehyde content of L. edodes was stable during the growth process. However, the formaldehyde content after the drying process showed 3-4-fold increase. For example, in the dried shiitake mushrooms, the formaldehyde content ranged from 100 to $230 \mathrm{mg} / \mathrm{kg}$, in contrast to $8-24 \mathrm{mg} / \mathrm{kg}$ in fresh ones [14]. Xu et al. indicated that the enzyme activities of GGT and C-S lyase were much higher under high temperature $\left(>45^{\circ} \mathrm{C}\right)$ than under $25^{\circ} \mathrm{C}$. These results demonstrated that the activation of the two key enzymes promoted reactions, leading to the production of a large amount of formaldehyde in L. edodes [26], which was well supported by our results in this study. This is the first report to show that the mRNA and protein expression levels of C-S lyase had significant and positive effects on the endogenous formaldehyde content of mushrooms.

Although the mRNA and protein expression levels of GGT were shown to be negatively correlated with the formaldehyde content, both GGT and C-S lyase were proved to be indispensable for the generation of endogenous formaldehyde in L. edodes. As previously reported, only the joint action of the two enzymes could promote the generation of endogenous formaldehyde [18], and GGT was the rate-limiting enzyme in the synthesis process of endogenous formaldehyde in L. edodes [29]. Our results showed that the activities of both of GGT and C-S lyase played a positive role in endogenous formaldehyde generation, implying the crucial effects of GGT in this process. GGT was also reported to be implicated in the transfer of amino acids across the cellular membrane and in metabolism of glutathione to cysteine by cleaving the glutamyl amide bond to preserve intracellular homeostasis by oxidative stress [31,32]. Besides, the transcription and function of genes are not synchronized in time and space. The presence of Ggtl homologous genes was also reported [33]. Moreover, compared with C-S Lyase, GGT has a much more complex structure and function. Despite the negative correlation of Ggtl and Leggt expression levels, we could not neglect their effects on the endogenous formaldehyde content in the mushroom. For a better control on the generation of endogenous formaldehyde in L. edodes, further studies should focus on the expression regulation of $\mathrm{Ggtl}$ and $\mathrm{Csl}$ at the transcription level.

Our study did not involve the influence of other potential metabolic pathways on the generation of endogenous formaldehyde, and whether other enzymes are implicated in the flavor metabolism pathways also needs to be investigated in future studies.

\section{Materials and Methods}

\subsection{Fungal Strain and Culture Conditions}

A dikaryotic strain of basidiomycete Lentinula edodes strain W1 (preserved in the Institute of Applied Mycology, Huazhong Agricultural University, Wuhan, China) was used in this study [34]. The L. edodes samples were obtained at five different stages: mycelia (used as control) and four fruiting body stages (grey, young fruiting body, immature fruiting body and mature fruiting body). Briefly, the mycelia were cultivated on $25 \mathrm{~mL}$ CYM liquid medium ( $2 \%$ glucose, $0.2 \%$ yeast extracts, $0.2 \%$ peptone, $0.1 \% \mathrm{~K}_{2} \mathrm{HPO}_{4}, 0.05 \% \mathrm{MgSO}_{4}$ and $0.046 \% \mathrm{KH}_{2} \mathrm{PO}_{4}$ ) in a conical flask and collected after growth of 12 days. Next, a conventional fruiting treatment was conducted as previously described [35]. The samples of grey (5-10 $\mathrm{mm}$ in cap diameter), young fruiting body (15-20 $\mathrm{mm}$ in cap diameter), immature fruiting 
body (with partial veil not ruptured) and mature fruiting body (with partial veil entirely ruptured) were harvested separately during fruiting treatment (Figure 6) [36]. The collected mushroom samples were immediately frozen in liquid nitrogen and stored at $-80{ }^{\circ} \mathrm{C}$ for further use. All samples were collected in three biological replications.

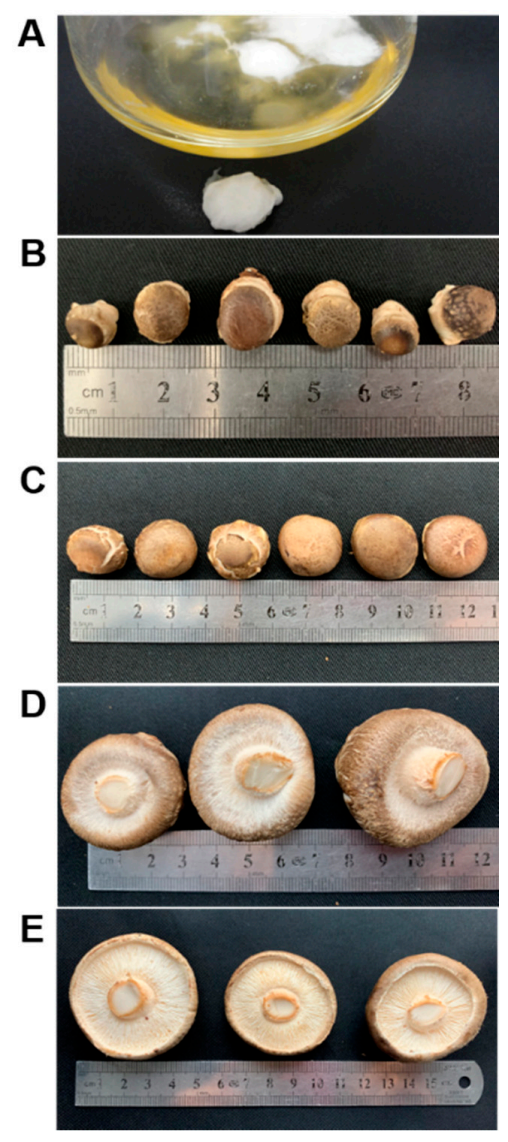

Figure 6. Five growth stages of L. edodes strain W1. (A) Mycelia. (B) Grey (5-10 mm in cap diameter). (C) Young fruiting body (15-20 mm in cap diameter). (D) Immature fruiting body (with partial veil not ruptured). (E) Mature fruiting body (with partial veil entirely ruptured).

\subsection{RNA Isolation and Real-Time Quantitative PCR}

Total RNA was isolated using RNAiso plus (TaKaRa, Kusatsu, Japan) according to the manufacturer's instructions [37]. The total RNA concentration and purity were detected using a Nano Drop 2000 spectrophotometer (Thermo Scientific, Wilmington, DE, USA; $2.0<$ A260/A280 < 2.2). The integrity of RNA was checked by electrophoresis on $1 \%$ agarose gel, and the three bands of 28S, $18 \mathrm{~S}$ and 5S could be clearly observed (Supplementary Figure S1).

Then, $20 \mu \mathrm{L}$ cDNA was synthesized from $1 \mu \mathrm{g}$ of total RNA using the HiScript II Q RT SuperMix for qPCR (+ gDNA wiper) kit (Vazyme Biotech, Nanjing, China) according to the manufacturer's instructions. Next, the CDNA was two-fold diluted with double-distilled water and stored at $-20^{\circ} \mathrm{C}$ for quantitative RT-PCR analysis. Specific primers were designed for quantitative RT-PCR analysis of the tested genes, such as Ggtl, encoding Leggt ( $\gamma$-glutamyl transpeptidase); Csl, encoding Lecsl (L. edodes C-S lyase, L. edodes genome Gene ID: LE01Gene02830) and $\beta$-actin gene (Actinl, encoding L. edodes $\beta$-actin, $L$. edodes genome Gene ID: LE01Gene01050; Supplementary Table S1) [33].

Quantitative RT-PCR was performed using a CFX Connect real-time PCR system (BIO-RAD). Each reaction consisted of $0.4 \mu \mathrm{L}$ each of the forward and reverse primers $(10 \mu \mathrm{M}), 1 \mu \mathrm{L}$ of two-fold diluted cDNA, $5 \mu \mathrm{L}$ of $2 \times$ Taq Master Mix (Vazyme Biotech, Nanjing, China) and $3.2 \mu \mathrm{L}$ of double-distilled water. The qRT-PCR was performed at $95^{\circ} \mathrm{C}$ for $3 \mathrm{~min}$, followed by 40 cycles of $95^{\circ} \mathrm{C}$ for $20 \mathrm{~s}, 60^{\circ} \mathrm{C}$ for 
$30 \mathrm{~s}, 72{ }^{\circ} \mathrm{C}$ for $30 \mathrm{~s}$ and then maintaining at $72{ }^{\circ} \mathrm{C}$ for $10 \mathrm{~min}$ in a 96 -well reaction plate. The specificity and identity of PCR products were verified by melting curve analysis to distinguish specific PCR products from the primer dimmer-caused nonspecific PCR. The existence of a single peak proved each PCR product was specific.

The relative expression was calculated using the $2^{-\Delta \Delta C T}$ method as previously described [38]. The expression of Actinl was used as an internal reference [39]. The expressions during the mycelium stage were taken as control. All PCR experiments were performed in three biological and three technical replications (the maximum difference in $\mathrm{Ct}$ was 0.5 ).

\subsection{Extraction of Total Protein and Western Blot Analysis}

Total protein of L. edodes was extracted as previously reported [40]. Briefly, $0.1 \mathrm{~g}$ of mycelia or fruiting body powder from each group (three replicates for each group) was mixed with $0.5 \mathrm{~mL}$ of extraction buffer ( $0.5 \mathrm{M}$ Tris- $\mathrm{HCl}, 50 \mathrm{mM}$ EDTA, $0.1 \mathrm{M} \mathrm{NaCl}$ and $40 \mathrm{mM}$ dithiothreitol). The supernatants were collected after extraction for $10 \mathrm{~min}$ and centrifugation at $10,000 \times g$ for $15 \mathrm{~min}$ at $4{ }^{\circ} \mathrm{C}$ to remove the insoluble substance. Next, the same volume of saturated Tris-phenol was added to the supernatants, followed by the addition of five volumes of pre-cooled $0.1 \mathrm{M}$ ammonium acetate in methanol to precipitate the protein. After washing with pre-cooled $80 \%$ acetone several times, the precipitated proteins were resolubilized and denatured for $10 \mathrm{~min}$ in $40 \mu \mathrm{L}$ solution buffer $(7 \mathrm{M}$ urea, $50 \mathrm{mM}$ Tris- $\mathrm{HCl}, 25 \mathrm{mM}$ EDTA, $10 \mathrm{mM} \mathrm{NaCl}$ and $60 \mathrm{mM}$ dithiothreitol). Finally, the pelleted proteins were diluted to $200 \mu \mathrm{L}$ for further analysis. The concentration of the total protein was tested by the Coomassie Brilliant Blue G250 method [41], and the quality of protein was checked by 10\% SDS-PAGE (Supplementary Figure S2) [42].

Western blot was used to analyze the expression of $\gamma$-glutamyl transpeptidase (Leggt, EC 2.3.2.2) and S-alkyl-L-cysteine sulfoxide lyase (Lecsl, EC 4.4.1.4) at different growth stages of L. edodes. After $50 \mu \mathrm{g}$ of each protein sample was run on 10\% SDS-PAGE gels (Bio-Rad Mini, Hercules, CA, USA), Western blot was performed by standard protocols using 1:200 anti-Leggt and anti-Lecsl polyclonal antibody sera. The antibodies against Leggt and Lecsl were raised by immunizing rabbits with the mixture of purified recombinant protein, which was expressed in Escherichia coli BL21 and purified by Ni-NTA Agarose column (Genscript, Nanjing, China) and Freund's adjuvant [43]. The specificity of polyclonal antibodies was detected by Western blot. The results showed that anti-Leggt polyclonal antibody sera had special bands at $68 \mathrm{kDa}, 45 \mathrm{kDa}$ and $23 \mathrm{kDa}$ and anti-Lecsl polyclonal antibody sera had special band at $54 \mathrm{kDa}$, respectively. 1:50,000 horseradish peroxidase conjugated secondary antibody (BOSTER, Wuhan, China). Meanwhile, the $\beta$-actin antibody (BOSTER, Wuhan, China) was treated with the same protocol as an internal control [21].

\subsection{Enzyme Activity Assays}

GGT activity was determined by the transfer rate of $\gamma$-glutamyl from $\gamma$-glutamyl $p$-nitroanilide (GPNA) as reported by Liu et al. [18]. The mixture including $1 \mathrm{~mL}$ crude enzyme extract from $L$. edodes, $1 \mathrm{~mL}$ GPNA $(3.5 \mathrm{mM})$ and $3 \mathrm{~mL}$ Tris- $\mathrm{HCl}(0.5 \mathrm{M}, \mathrm{pH}=7.6)$ was incubated at $37^{\circ} \mathrm{C}$ for $20 \mathrm{~min}$ and the reaction was stopped by adding $3 \mathrm{~mL}$ of $1.5 \mathrm{M}$ cold $\left(4^{\circ} \mathrm{C}\right)$ acetic acid. Then, the amount of p-nitroaniline released was measured at $410 \mathrm{~nm}$. The specific activity of GGT was defined as the amount of enzyme that released $1 \mu \mathrm{mol}$ of p-nitroaniline from the substrate per min per g protein $(\mathrm{U} / \mathrm{g})$.

C-S lyase activity was measured as previously described with some modifications [44]. The mixture containing $0.3 \mathrm{~mL}$ crude enzyme extract from L. edodes, $0.5 \mathrm{~mL}$ S-ethyl-L-cysteine sulfoxide and $0.2 \mathrm{~mL}$ Tris- $\mathrm{HCl}(0.5 \mathrm{M}, \mathrm{pH}=7.6)$ was incubated at $37^{\circ} \mathrm{C}$ for $5 \mathrm{~min}$. The reaction was terminated by adding 1 $\mathrm{mL}$ trichloroacetic acid (TCA, 10\%). After supplementation with $1 \mathrm{~mL}$ 2,4-dinitrophenylhydrazine $(\mathrm{DNPH}, 0.1 \%, \mathrm{~m} / \mathrm{v})$ were added to the mixture was incubated for $5 \mathrm{~min}$ at $25^{\circ} \mathrm{C}$. Finally, $2.5 \mathrm{~mL} \mathrm{NaOH}$ $(2.5 \mathrm{M})$ was added to the mixture and incubated for $10 \mathrm{~min}$ at $25^{\circ} \mathrm{C}$. The absorbance of DNPH at 520 $\mathrm{nm}$ was measured. The specific activity of C-S lyase was expressed as units of enzyme per $\mathrm{g}$ of L.edodes protein $(\mathrm{U} / \mathrm{g})$. 


\subsection{Determination of Endogenous Formaldehyde Content in L. edodes}

Steam distillation was used to extract formaldehyde from $L$. edodes at each growth stage. Each sample was supernatant of $4 \mathrm{~g}$ L. edodes homogenized with $100 \mathrm{~mL}$ Tris- $\mathrm{HCl}(0.5 \mathrm{M}, \mathrm{pH}=7.6)$ buffer and $10 \mathrm{~mL} \mathrm{10 \%} \mathrm{(v/v)} \mathrm{phosphoric} \mathrm{acid} \mathrm{aqueous} \mathrm{solution} \mathrm{in} \mathrm{a} 250 \mathrm{~mL}$ distillation flask. Water vapor was collected into a $150 \mathrm{~mL}$ flask, and then immersed in an ice-bath. The distillation process was stopped when $6070 \mathrm{~mL}$ of the distillate was collected and made up to $100 \mathrm{~mL}$ by deionized water. Formaldehyde in the distillate was derived by adding $1 \mathrm{~mL}$ of the distillate, $3.5 \mathrm{~mL}$ acetate buffer $(0.1 \mathrm{M}, \mathrm{pH}=4.0)$ and $0.5 \mathrm{~mL} \mathrm{DNPH}(3 \mathrm{mg} / \mathrm{mL})$ into a centrifuge tube at $25^{\circ} \mathrm{C}$ for $15 \mathrm{~min}$. Then the derived sample was filtered through a $0.22 \mu \mathrm{m}$ filter for HPLC analysis. The formaldehyde derivative (formaldehyde-DNPH) of each group was separated and determined by a reverse-phase HPLC system (Waters, Milford, MA, USA). The mobile phase was composed of $0.05 \%$ acetic acid in acetonitrile and $0.05 \%$ acetic acid in water. The injection volume was $20 \mu \mathrm{L}$. All samples were detected at $355 \mathrm{~nm}$ as previously reported [18].

\subsection{Data Analysis}

All experimental data were presented as the mean \pm standard deviation from at least three independent experiments. The ANOVA tests of statistical significance were performed by Duncan's multiple range tests using SPSS 20.0. $p$-values of $<0.05$ and $<0.01$ were accepted as significant and remarkable significant difference, respectively. The correlations of formaldehyde content with the expression levels of Ggtl, Csl, Leggt and Lecsl as well as GGT and C-S lyase activities were analyzed separately by Pearson correlation coefficient and trend of data using SPSS 20.0.

\section{Conclusions}

In this study, we reported for the first time the mRNA and protein expression levels and the activities of GGT and C-S lyase as well as their correlations with the endogenous formaldehyde content in L. edodes at different growth stages. The protein expression levels of Leggt and Lecsl were consistent with the mRNA expression levels of Ggtl and Csl. Additionally, the expression levels of GGT were decreased while those of C-S lyase were increased with the growth and development of Lentinula edodes. Furthermore, the enzyme activities and formaldehyde content were found to be the lowest in the mycelium stage. Our results demonstrated that the expression levels of Csl and Lecsl as well as the enzyme activities of C-S lyase and GGT were positively correlated with formaldehyde content during the development of L. edodes. These findings revealed the role of GGT and C-S lyase in generating endogenous formaldehyde at the molecular level. They also provided a molecular basis for regulating endogenous formaldehyde in the process of L. edodes growth.

Supplementary Materials: The supplementary materials are available online. Supplementary Figure S1: Agarose gel electrophoresis of RNA extracted from L. edodes at different growth stages; Supplementary Figure S2: SDS-PAGE of L. edodes total protein at different growth stages; Supplementary Table S1: Quantitative primer information of Ggtl, Csl and Actinl.

Author Contributions: X.L., Y.L. and W.H. conceived and designed the experiments. X.L., S.G. and Z.H. prepared the experiment materials. X.L. performed the experiments and analyzed the data. X.L., Y.L. and X.F. wrote the manuscript. Y.B., Y.L. and W.H. provided intellectual input and revised the manuscript. All authors read and approved the final manuscript.

Funding: This research was funded by the Natural Science Foundation of China (31601434), the Major Projects of Technological Innovation of Hubei Province (2017ABA148), the Innovation Center of Agricultural Science and Technology of Hubei Province (2016-620-000-001-044), the China Postdoctoral Science Foundation (2016T90701).

Conflicts of Interest: The authors declare no conflict of interest.

\section{References}

1. Philippoussis, A.; Diamantopoulou, P.; Israilides, C. Productivity of agricultural residues used for the cultivation of the medicinal fungus Lentinula edodes. Int. Biodeter. Biodegr. 2007, 59, 216-219. [CrossRef] 
2. Bruhn, J.N.; Mihail, J.D.; Pickens, J.B. Forest farming of shiitake mushrooms: An integrated evaluation of management practices. Bioresour. Technol. 2009, 100, 6472-6480. [CrossRef] [PubMed]

3. Finimundy, T.C.; Dillon, A.J.P.; Henriques, J.A.P.; Ely, M.R. A review on general nutritional compounds and pharmacological properties of the Lentinula edodes mushroom. Food Nutr. Sci. 2014, 5, 1095-1105.

4. Choi, Y.; Lee, S.M.; Chun, J.; Lee, H.B.; Lee, J. Influence of heat treatment on the antioxidant activities and polyphenolic compounds of Shiitake (Lentinus edodes) mushroom. Food Chem. 2006, 99, 381-387. [CrossRef]

5. Chen, C.; Ho, C. High-performance liquid chromatographic determination of cyclic sulfur compounds of Shiitake mushroom (Lentinus edodes Sing.). J. Chromatogr. A 1986, 356, 455-459. [CrossRef]

6. Hiraide, M.; Miyazaki, Y.; Shibata, Y. The smell and odorous components of dried shiitake mushroom, Lentinula edodes I: Relationship between sensory evaluations and amounts of odorous components. J. Wood Sci. 2004, 50, 358-364. [CrossRef]

7. Yasumoto, K.; Iwami, K.; Mitsuda, H. A new sulfur-containing peptide from Lentinus edodes acting as a precursor for lenthionine. Agric. Biol. Chem. 1971, 35, 2059-2069. [CrossRef]

8. Yasumoto, K.; Iwami, K.; Mitsuda, H. Enzyme-catalized evolution of lenthionine from lentinic acid. Agric. Biol. Chem. 1971, 35, 2070-2080. [CrossRef]

9. Yamazaki, H.; Ogasawara, Y.; Sakai, C.; Yoshiki, M.; Makino, K.; Kishi, T.; Kakiuchi, Y. Formaldehyde in Lentinus edodes (in giapponese). J. Food Hyg. Soc. Jpn. 1980, 21, 165-170. [CrossRef]

10. Yasumoto, K.; Iwami, K.; Mitsuda, H. Enzymatic formation of shiitake aroma from nonvolatile precursor (s)-lenthionine from lentinic acid. Mushroom Sci. 1976, 9, 371-383.

11. Weng, X.; Chon, C.H.; Jiang, H.; Li, D. Rapid detection of formaldehyde concentration in food on a polydimethylsiloxane (PDMS) microfluidic chip. Food Chem. 2009, 114, 1079-1082. [CrossRef]

12. Huang, T.; Hong, L.; Yuan, X.; Yan, L.; Gang, Z. Preparation and characterization of a novel absorber for formaldehyde. Proc. Int. Conf. Biol. Eng. Pharm. (BEP 2016) 2016, in press.

13. Tashkov, W. Determination of formaldehyde in foods, biological media and technological materials by headspace gas chromatography. Chromatographia 1996, 43, 625-627. [CrossRef]

14. Mason, D.; Sykes, M.; Panton, S.; Rippon, E. Determination of naturally-occurring formaldehyde in raw and cooked Shiitake mushrooms by spectrophotometry and liquid chromatography-mass spectrometry. Food Addit. Contam. 2004, 21, 1071-1082. [CrossRef] [PubMed]

15. Okada, S.; Iga, S.; Isaka, H. Studies on formaldehyde observed in edible mushroom shiitake, Lentinus edodes (Berk.) Sing (in giapponese). J. Hyg. Chem. 1972, 18, 353-357.

16. Tate, S.S.; Meister, A. $\gamma$-Glutamyl transpeptidase from kidney. Methods Enzym. 1985, 113, 400-419.

17. Kuettner, E.B.; Hilgenfeld, R.; Weiss, M.S. The active principle of garlic at atomic resolution. J. Biol. Chem. 2002, 277, 46402-46407. [CrossRef]

18. Liu, Y.; Yuan, Y.; Lei, X.Y.; Yang, H.; Ibrahim, S.A.; Huang, W. Purification and characterisation of two enzymes related to endogenous formaldehyde in Lentinula edodes. Food Chem. 2013, 138, 2174-2179. [CrossRef]

19. Liu, Y.; Lei, X.Y.; Chen, L.F.; Bian, Y.B.; Yang, H.; Ibrahim, S.A.; Huang, W. A novel cysteine desulfurase influencing organosulfur compounds in Lentinula edodes. Sci. Rep. 2015, 5, 10047. [CrossRef]

20. Gao, S.; Wang, G.Z.; Huang, Z.; Lei, X.; Bian, Y.; Liu, Y.; Huang, W. Selection of reference genes for qRT-PCR analysis in Lentinula edodes after hot-air drying. Molecules 2018, 24, 136. [CrossRef]

21. Rani, N.; Nowakowski, T.; Zhou, H.; Godshalk, S.E.; Lisi, V.; Kriegstein, A.; Kosik, K. A primate lncRNA mediates notch signaling during neuronal development by sequestering miRNA. Neuron 2016, 90, 1174-1188. [CrossRef] [PubMed]

22. Okada, T.; Suzuki, H.; Wada, K.; Kumagai, H.; Fukuyama, K. Crystal structure of the $\gamma$-glutamyltranspeptidase precursor protein from Escherichia coli structural changes upon autocatalytic processing and implications for the maturation mechanism. J. Biol. Chem. 2007, 282, 2433-2439. [CrossRef] [PubMed]

23. Boanca, G.; Sand, A.; Barycki, J.J. Uncoupling the enzymatic and autoprocessing activities of helicobacter pylori -Glutamyltranspeptidase. J. Biol. Chem. 2006, 281, 19029-19037. [CrossRef] [PubMed]

24. Martin, M.N.; Slovin, J.P. Purified gamma-glutamyl transpeptidases from tomato exhibit high affinity for glutathione and glutathione S-conjugates. Plant Physiol. 2000, 122, 1417-1426. [CrossRef]

25. Huang, J.; Luo, H.; Li, J. Gene cloning of $\gamma$-Glutamyltranspeptidase and its relationship to endogenous formaldehyde in shiitake mushroom (Lentinus edodes). Adv. J. Food Sci. Technol. 2016, 12, 579-587. [CrossRef]

26. Xu, L.; Fang, X.; Wu, W.; Chen, H.; Mu, H.; Gao, H. Effects of high-temperature pre-drying on the quality of air-dried shiitake mushrooms (Lentinula edodes). Food Chem. 2019, 285, 406-413. [CrossRef] 
27. Huang, Z.; Lei, X.; Feng, X.; Gao, S.; Wang, G.; Bian, Y.; Huang, W.; Liu, Y. Identification of a heat-inducible element of cysteine desulfurase gene promoter in Lentinula edodes. Molecules 2019, 24, 2223. [CrossRef]

28. Li, J.; Song, J.; Huang, J.; Wu, N.; Zhang, L.; Jiang, T. Study on key enzymes of endogenous formaldehyde metabolism and it's content in shiitake mushrooms (Lentinus Edodes). J Chin. Inst. Food Sci. Technol. 2013, 13, 213-218.

29. Aberkane, H.; Frank, P.; Galteau, M.; Wellman, M. Acivicin induces apoptosis independently of gamma-glutamyltranspeptidase activity. Biochem. Biophys. Res. Commun. 2001, 285, 1162-1167. [CrossRef]

30. Burgos-Barragan, G.; Wit, N.; Meiser, J.; Dingler, F.A.; Pietzke, M.; Mulderrig, L.; Pontel, L.B.; Rosado, I.V.; Brewer, T.F.; Cordell, R.L.; et al. Mammals divert endogenous genotoxic formaldehyde into one-carbon metabolism. Nature 2017, 548, 549-554. [CrossRef]

31. Pompella, A.; Franzini, M.; Emdin, M.; Passino, C.; Paolicchi, A. Gamma-glutamylaransferase activity in human atherosclerotic plaques: Origin, prooxidant effects and potential roles in progression of disease. Atheroscler. Supp. 2007, 8, 95. [CrossRef]

32. Lim, J.S.; Yang, J.H.; Chun, B.Y.; Kam, S.; Jr, J.D.; Lee, D.H. Is serum gamma-glutamyltransferase inversely associated with serum antioxidants as a marker of oxidative stress? Free Radic. Bio. Med. 2004, 37, 1018-1023. [CrossRef] [PubMed]

33. Chen, L.; Gong, Y.; Cai, Y.; Liu, W.; Zhou, Y.; Xiao, Y.; Xu, Z.; Liu, Y.; Lei, X.; Wang, G. Genome sequence of the edible cultivated mushroom Lentinula edodes (Shiitake) reveals insights into lignocellulose degradation. PLoS ONE 2016, 11, e0160336. [CrossRef] [PubMed]

34. Kirk, P.M.; Cannon, P.F.; Minter, D.W.; Stalpers, J.A. Dictionary of the Fungi. Mycol. Res. 2009, 113, 908-910.

35. Gong, W.; Xu, R.; Xiao, Y.; Zhou, Y.; Bian, Y. Phenotypic evaluation and analysis of important agronomic traits in the hybrid and natural populations of Lentinula edodes. Sci. Hortic. 2014, 179, 271-276. [CrossRef]

36. Leung, G.S.W.; Zhang, M.; Xie, W.J.; Kwan, H.S. Identification by RNA fingerprinting of genes differentially expressed during the development of the basidiomycete Lentinula edodes. Mol. Gen. Genet. 2000, 262, 977-990. [CrossRef]

37. Wang, G.Z.; Ma, C.J.; Luo, Y.; Zhou, S.S.; Zhou, Y.; Ma, X.L.; Cai, Y.L.; Yu, J.J.; Bian, Y.B.; Gong, Y.H.; et al. Proteome and transcriptome reveal involvement of heat shock proteins and indoleacetic acid metabolism process in Lentinula edodes thermotolerance. Cell. Physiol. Biochem. 2018, 50, 1617-1637. [CrossRef]

38. Pfaffl, M.W. A new mathematical model for relative quantification in real-time RT-PCR. Nucleic Acids Res. 2001, 29, e45. [CrossRef]

39. Masaru, N.; Maki, K.; Hisayuki, W.; Machiko, O.; Kumiko, S.; Toshikazu, T.; Katsuhiro, K.; Toshitsugu, S. Important role of fungal intracellular laccase for melanin synthesis: Purification and characterization of an intracellular laccase from Lentinula edodes fruit bodies. Microbiology 2003, 149, 2455-2462.

40. Cai, Y.; Gong, Y.; Liu, W.; Hu, Y.; Chen, L.; Yan, L.; Zhou, Y.; Bian, Y. Comparative secretomic analysis of lignocellulose degradation by Lentinula edodes grown on microcrystalline cellulose, lignosulfonate and glucose. J. Proteom. 2017, 163, 92-101. [CrossRef]

41. Bradford, M.M. A rapid method for the quantitation of microgram quantities of protein utilizing the principle of protein-dye binding. Anal. Biochem. 1976, 72, 248-254. [CrossRef]

42. Laemmli, U.K. Cleavage of structural proteins during the assembly of the head of bacteriophage T4. Nature 1970, 227, 680-685. [CrossRef] [PubMed]

43. Wachino, J.; Shibayama, K.; Suzuki, S.; Yamane, K.; Mori, S.; Arakawa, Y. Profile of Expression of Helicobacter pylori $\gamma$-Glutamyltranspeptidase. Helicobacter 2010, 15, 184-192. [CrossRef]

44. Yasumoto, K.; Iwami, K. S-Substituted l-cysteine sulfoxide lyase from shiitake mushroom. Methods Enzym. 1987, 143, 434-439.

Sample Availability: Samples of the constructs are available from the authors. 